\title{
El régimen municipal de la isla de Cuba en la segunda mitad del siglo XIX
}

\author{
M. ${ }^{a}$ de los Angeles Hijano Pérez
}

Universidad Autónoma de Madrid

Con este artículo se pretende ofrecer una panorámica del régimen municipal cubano en la segunda mitad del siglo XIX, que sea útil para completar la exigua información existente sobre la materia. Conviene resaltar el carácter innovador del artículo, puesto de manifiesto en la utilización de unas fuentes documentales, prácticamente inéditas, los Proyectos de Ordenanzas Municipales y el Proyecto de Reglamento de Régimen Local de 1854, que han sido la base para establecer las conclusiones.

Las normas de carácter local, las Ordenanzas Municipales, se perfilan como un elemento imprescindible para valorar aspectos tan importantes como la participación de los municipios cubanos y de sus autoridades, en la elaboración de la normativa local y, en última instancia, su análisis permite establecer cuál fue la relación de la colonia con respecto a la metrópoli, siendo el resultado obtenido el de una notoria centralización por parte de la monarquía española, en detrimento de la autonomía isleña.

La bibliografía sobre el municipio indiano, y especialmente sobre el municipio cubano, se ha caracterizado, al menos en este siglo, por una falta de análisis minuciosos. ${ }^{1}$ Sin duda, se trata de un tema falto de estudios, sobre todo si lo comparamos con la cantidad de trabajos publicados sobre el municipio mexicano, peruano o chileno. ${ }^{2}$ De igual modo, una publicación tan prestigiosa como la Historia del Mundo Moderno de Cambridge, apenas dedica unas lí-

1 Pérez de Tudela, Juan: El Estado Indiano, en "Enciclopedia de Historia de España", dirigida por Miguel Artola, Madrid, 1988, págs. 495-592. Este autor incide en la "copiosa e irregular producción relativa a la organización y funciones políticas del municipio".

2 Entre otros, Flores Olea, Aurora: Los regidores de la ciudad de México en la primera mitad del siglo XVII, en "Estudios de Historia Novohispana", México, 1970, III. Alvarado Morales, M.: El Cabildo y el regimiento de la ciudad de México en el siglo XVII. Un ejemplo de oligarquía criolla, en "Historia Mexicana", 112, México, 1979. Lohmann Villena, G.: Los regidores del Cabildo de Lima desde 1535 a 1635. Estudio de un grupo de dominio, en "Revista Internacional", 127-130, 1972. Alemparte: El Cabildo en Chile colonial. Orígenes municipales de las repúblicas hispanoamericanas, Santiago de Chile, 1968. 
neas a temas cubanos $\mathrm{y}$, por supuesto, las referencias al municipio son casi inexistentes, ${ }^{3}$ siendo muy abundantes los ejemplos de esta clase. $^{4}$

Recientemente se está tratando de superar la falta de interés en las investigaciones sobre temas histórico-jurídicos en las colonias, aunque Cuba sigue siendo un pais, por razones obvias, falto de interés. En este sentido, la revista "Ayer", ${ }^{5}$ dirigida por el profesor Miguel Artola, ha dedicado un número monográfico para analizar la historia colonial hispanoamericana y la historia contemporánea iberoamericana, poniendo especial énfasis en el ámbito jurídico-político. En dicha publicación, México, Chile, Perú, Argentina y Centroamérica continúan siendo los países protagonistas del contenido, quedando Cuba al margen. ${ }^{6}$ En ese resurgir del interés por la historia iberoamericana, ha sido crucial la conmemoración del $\mathrm{V}$ centenario, pero, en cualquier caso, Cuba continúa apartada del interés de los historiadores, salvo en los temas referidos al régimen castrista. ${ }^{7}$ Como he señalado, las publicaciones españolas, latinoamericanas, europeas y norteamericanas más actuales, se han interesado por los asuntos latinoamericanos, pero siempre prestando escaso interés

3 Historia del Mundo Moderno, Cambridge University Press, vols., I, IX y XII, Barcelona, 1988. Sólo tres tomos de la colección dedican algunas páginas a Cuba y, además, se centran en la colonización y la independencia, quedando el siglo XIX prácticamente olvidado.

4 Así, una extensa monografía dedicada a Cuba omite cualquier análisis de los temas municipales. Thomas, Hugh: Cuba, la lucha por la libertad 1762-1909, 1909-1958 y 1958-1970, III vols., Barcelona, 1973.

5 Soberanes Fernández, J.L., ed.: El primer constitucionalismo iberoamericano, "Ayer" n." 8, Madrid, 1992.

6 Los artículos de José Luis Soberanes Fernández, El primer constitucionalismo mexicano; de Mario García Laguardia, De Bayona a la República Federal. Los primeros documentos constitucionales de Centroamérica; de Carlos Restrepo Piedrahita, Las primeras constituciones políticas de Colombia y Venezuela; de Domingo García Belaunde, Los inicios del constitucionalismo peruano (1821-1842), y de Germán J. Bidart Campos, El proceso político-constitucional de la República Argentina desde 1810 a la actualidad, constituyen una muestra importante del renacido interés por esta temática.

7 Sobre el particular, resulta de notable interés un libro donde se analiza la historia reciente de Cuba, haciendo hincapié en la influencia que el régimen castrista ejerció, por sus implicaciones políticas e ideológicas entre los intelectuales europeos. Verdes-Leroux, Jeannine: La lune et le caudillo. Le rêve des intellectuels et le régime cubain (1959-1971). París, 1989. 
a los siglos XIX y XX, tal y como se pone de manifiesto en otro número de la mencionada revista. ${ }^{8}$

Ante las numerosas carencias bibliográficas presentadas por las investigaciones sobre el régimen municipal en Ultramar, ${ }^{9}$ se trata de ofrecer una panorámica de la situación de los municipios cubanos en la segunda mitad del siglo XIX, en función del análisis de la legislación emanada del Estado español en sus textos constitucionales y en los decretos referidos a los territorios ultramarinos, sin olvidar la actividad normativa de dichos municipios, así como su participación en los procesos de reforma municipal. ${ }^{10}$ Para ese fin, se han tomado como fuentes documentales las normas de carácter local en su doble acepción: las elaboradas por los municipios cubanos y sus autoridades y las dictadas por el Estado español. En última instancia, la normativa permite establecer cuál fue la relación de la colonia con respecto a la metrópoli, siendo el resultado obtenido, como se verá, el de una notoria centralización por parte de la monarquía española, en detrimento de la autonomía isleña.

\section{Las ordenanzas municipales}

Las Ordenanzas municipales, al ser elaboradas por los propios municipios, ${ }^{11}$ constituyen la fuente de normativa local más relevante. Basándome en una serie de textos de esta naturaleza, establece-

8 Malamud, Carlos D.: La Historia Contemporánea latinoamericana en 1990, en “Ayer", n. ${ }^{\circ} 2$, págs. 49-60, Madrid, 1991.

9 Los temas municipales cubanos sólo se han abordado en una breve serie de títulos que, además, se publicaron a finales del siglo pasado. Bonilla, J.M.: Breve tratado de Derecho administrativo español, general del reino y especial de la Isla de Cuba, La Habana, 1842. Govin Torres, A.: Las leyes especiales, La Habana, 1880. Jimenez de la Romera, W.: Cuba, Puerto Rico y Filipinas, Barcelona, 1887. Carrera Juztiz, F.: Introducción a la historia de las instituciones locales de Cuba, La Habana, 1905.

10 Los temas relacionados con el municipio, aunque con una perspectiva distinta de la planteada aquí, han sido analizados brevemente en un reciente trabajo. Rieu-Millan, Marie Laure: Los diputados americanos en las Cortes de Cádiz, Madrid, 1990, págs. 220-241.

11 Esta afirmación resulta cierta en el caso de los municipios metropolitanos, pero no ocurre así en las colonias, donde la elaboración de estos textos podrá contar con la participación de los Ayuntamientos, pero éstos no ejercerán ese derecho por sí solos. 
ré unas características generales de la normativa local emanada de los municipios en estas fechas y un análisis comparativo entre éstos y la misma normativa que rige en España en esos momentos. ${ }^{12}$ Se abordará también el estudio de los contenidos de algunas Ordenanzas, en la medida que permiten configurar una imagen de cómo funcionaban dichos municipios durante la dominación española y cuáles eran los problemas más acuciantes.

A diferencia de lo que ocurre en España, esta normativa no es elaborada por los propios Ayuntamientos, entendiendo éstos como el grupo de personas que ocupa la cabeza de los municipios y, en suma, la autoridad suprema dentro de los mismos, ${ }^{13}$ sino que la participación de éstos en las tareas normativas está siempre encaminada a cumplir los dictados de los gobernadores civiles o de cualquier otra autoridad de la Isla.

Los aspectos más reseñables para el estudio de esta documentación son los referidos a su elaboración, aprobación-confirmación y contenidos, pues en los dos primeros se obtienen respuestas a la articulación de los poderes locales con respecto al Estado, es decir, a las relaciones existentes entre municipios y Estado, mientras el tercero aporta informaciones acerca de cuáles eran las preocupaciones de los ayuntamientos, sus actividades económicas, así como del alcance y límites de sus competencias. Sin embargo, durante los primeros años de la colonización era habitual que las Ordenanzas fuesen dictadas también por los virreyes o las Audiencias, pues en muchas ocasiones era necesario legislar sobre cuestiones concretas que afectaran a núcleos de población más amplios que un solo municipio. No obstante, para entrar en vigor y, sobre todo, para adquirir carácter de norma de obligado cumplimiento, era preciso contar

12 Para profundizar en el estudio del régimen local español en estas fechas, conviene la consulta de una obra, casi paradigmática, donde se unen los análisis institucionales, económicos y sociológicos. Merchán Alvarez, Carlos: Gobierno municipal y administración local en la España del Antiguo Régimen, Madrid, 1988.

13 Habitualmente, se alude al Ayuntamiento como un acto y no como una entidad. Beneyto, Historia de la Administración española e hispanoamericana, Madrid, 1958, pág. 273. Sin embargo, al referimos a la organización político-administrativa del municipio indiano, es preciso diferenciar entre Concejo o Cabildo - Antiguo Régimen - y Ayuntamiento etapa constitucional- 
con la aprobación de las instituciones superiores, tanto de la colonia, como de la metrópoli.

\section{Las ordenanzas municipales durante el Antiguo Régimen. Sistemas de aprobación}

\section{La Corona de Castilla}

En el caso español hay varias opciones para conseguir dicha aprobación, bien nos estemos refiriendo al Antiguo Régimen, bien a la etapa constitucional. Algo similar ocurre en el caso de las colonias ya que, a pesar de la existencia de un derecho indiano, desde un principio se trató de aplicar en los territorios conquistados el derecho vigente en Castilla.

En síntesis, durante el Antiguo Régimen, en los territorios españoles de la Corona de Castilla, las Ordenanzas municipales podían ser aprobadas siguiendo tres supuestos distintos:

1.-La aprobación era realizada por el señor en aquellos municipios donde éste poseía un dominio jurisdiccional sobre el territorio. En caso contrario, aunque la clase de dominio fuera un señorío, presenciaríamos una aprobación idéntica a la de los territorios de realengo, pues nos encontraríamos ante un señorío meramente territorial, donde el señor ejerce su poder sobre una zona con el único fin de obtener una renta, siendo su aprovechamiento exclusivamente económico, sin ninguna atribución jurisdiccional.

2.-La aprobación era realizada por el corregidor en aquellos municipios pertenecientes a la jurisdicción regia donde aquél actuaba en nombre del rey, haciendo uso de las atribuciones que tenía encomendadas como representante directo en los municipios a su cargo. La razón de la presencia del corregidor en los pueblos respondía a un claro interés por parte de la monarquía de hacer extensivo el intervencionismo hasta los más alejados reductos del territorio.

3.-La aprobación era realizada por la Corona, que lo hacía siempre a través del Consejo de Castilla (máximo órgano institucio- 
nal del Antiguo Régimen) en aquellos municipios donde la monarquía disponía de un dominio no sólo económico, sino también jurisdiccional, a pesar de que esos municipios tuvieran como titular de la propiedad del territorio a un señor. En definitiva, la aprobación le correspondía en todos aquellos dominios sometidos a jurisdicción regia que estaban bajo su soberanía.

\section{Los territorios de Ultramar}

Sin embargo, los territorios coloniales no pueden ser incluidos en ninguno de estos apartados pues, desde un principio, contaron con una configuración jurisdiccional distinta, al tener que ejercer el monarca su soberanía en ellos por delegación. Además, las diferencias entre dominio señorial y dominio realengo establecidas para los territorios metropolitanos no pueden ser aplicadas, de forma idéntica, al caso de las colonias, pues se entiende que todos los territorios coloniales pertenecen a la soberanía $y$, por tanto, jurisdicción real, ${ }^{14}$ como se recoge en la legislación dictada para los territorios de Indias desde el momento de su conquista. ${ }^{15}$ Así pues, en el Antiguo Régimen la capacidad de aprobar, confirmar y sancionar las Ordenanzas municipales corresponde a la institución virreinal, pues el virrey representaba a la máxima instancia de poder ${ }^{16}$ y ostentaba la delegación de la misma en los territorios ultramarinos. No obstante, las Audiencias, aunque eran tribunales de justicia encargados de las apelaciones, también tuvieron una actividad importante en este sentido, ya que colaboraban con los virreyes y gobernadores en

14 Beneyto, Historia de la..., pág. 426. Según él, "Los indios son, desde el primer momento, vasallos de la Corona".

15 Recopilacion de Leyes de los Reynos de las Indias, Mandadas imprimir, y publicar por la Magestad Catolica del Rey Don Carlos II. Nuestro Señor. Va dividida en quatro tomos, con el Indice general, y al principio de cada Tomo el Indice especial de los titulos, que contiene. En Madrid: Por Ivlian de Paredes, Año de 1681. En Madrid: Por Ediciones Cultura Hispánica, Año de 1973. (Recop. Leyes de Indias), Libro Tercero, Titulo Primero. "De el dominio y iurisdicion Real de las Indias. Ley primera: Que las Indias Occidentales estèn siempre unidas à la Corona de Castilla, y no se puedan enagenar".

16 Sobre provisión del cargo, atribuciones de los Virreyes, etc., cfr. Recop. Leyes de Indias, Título Tercero, Ley primera a Ley Lxxiiii. 
cuestiones gubernativas. ${ }^{17} \mathrm{El}$ cargo de corregidor, ${ }^{18}$ por su parte, también fue trasladado a las colonias $\mathrm{y}$, de hecho, sabemos que en Cuba existía una red de Corregimientos que aún pervivía en el siglo XIX, ${ }^{19}$ aunque no está claro que en el Antiguo Régimen participara en el proceso de aprobación de las Ordenanzas de las colonias, como ocurría en los territorios de la Corona de Castilla. Las leyes que regulan las características de este cargo no hacen referencias a este asunto, aunque llama la atención la existencia de corregidores de Señorío, lo cual determina que, aun siendo escasos, también existieron titulares de Señoríos en las colonias, prácticamente desde el inicio de la conquista. ${ }^{20}$

\section{Las ordenanzas municipales a partir de la revolución liberal}

A partir de 1808 y, más concretamente, desde 1812, fecha en que se promulga la Constitución de Cádiz, la confirmación de las Ordenanzas municipales pasa a ser competencia de los representantes de la nación reunidos en Cortes, ${ }^{21}$ pero los avatares de la historia política española del siglo XIX configuran un penoso camino de ida y vuelta en la cuestión de la aprobación de estos textos. El panorama ofrecido en este particular puede resumirse señalando que los distintos cambios de régimen político - liberal/absolutista- determinarán la vuelta a las fórmulas instauradas por la Constitución de Cádiz o bien a las restauradas por el régimen absolutista. La dia-

17 Font Rius, José María: voz "Audiencias Indianas", Diccionario de Historia de España, 2." ed., I, Madrid, 1981, págs. 406-407.

18 Recop. Leyes de Indias, Libro V, Título II, 52 leyes, 144-153.

19 Este es un dato que podemos constatar a partir de la normativa local, ya que en unas Ordenanzas de 1862 se alude expresamente al Corregimiento de la Habana, como una de las instituciones que participa en la aprobación de las mismas. Ordenanzas de construcción para la ciudad de la Habana y pueblos de su término municipal. Habana, 1862, págs. 5-6.

20 Recop. Leyes de Indias, Libro V, Título II, Ley xxxii: "Que los salarios de los Corregidores de Señorio se paguen de los tributos dèl, y no de la Comunidad".

21 Embid Irujo, Antonio: Ordenanzas y reglamentos municipales en el derecho español, Madrid, 1978, pág. 84. 
léctica será, por tanto, muy clara: de un lado, retorno a los procedimientos utilizados durante el Antiguo Régimen (aunque su aplicación no sea estrictamente idéntica, dados los cambios sufridos por la sociedad) y, de otro, la vuelta a los acuñados por las Cortes de Cádiz (la constitución de 1812 será el punto de obligada referencia cada vez que se produzca un pronunciamiento militar, al menos hasta la muerte de Fernando VII). A partir de 1834 el panorama se hace más complejo, pues el régimen constitucional ya se encuentra asentado - no hay posibilidades de marcha atrás-, encontrando entonces que las diferencias dependerán de los principios defendidos por cada uno de los partidos que ocupen el poder, siendo entonces la dialéctica entre progresistas y moderados. ${ }^{22}$ Las cuestiones relativas a las Ordenanzas en particular y a los municipios en general serán entonces reguladas por Leyes de Ayuntamientos que recogen los principios de la burguesía en cada una de las dos vertientes reseñadas antes.

Estas serían pautas comunes, pero los municipios de las colonias cuentan, a partir de estas fechas, con un sistema distinto al de la metrópoli a la hora de aprobar sus Ordenanzas municipales. Hasta 1854 , fecha en que se redacta el Proyecto de bases y Reglamento para la reorganización de Ayuntamientos de la Isla de Cuba (poco antes de promulgarse en España la Ley de Ayuntamientos de 5 de julio de 1856), tenemos escasas referencias sobre la fórmula seguida para su aprobación, pero es evidente que no eran discutidas en las Cortes, ya que las cuestiones relativas al régimen municipal de las colonias no podían ser consideradas como un asunto a debatir por los representantes de la nación.

Después de 1856, estando en vigor la Ley de Ayuntamientos de 5 de julio del mismo año, hemos de entender que las competencias de los Ayuntamientos se regularán por dicha ley, aunque haya algunas variaciones con respecto a lo acontecido en los municipios metropolitanos, por el mero hecho de existir en Cuba algunas instituciones que no aparecen en los demás dominios españoles.

22 Para un estudio sobre estas cuestiones, cfr. García Fernández, Javier: El origen del municipio constitucional, Madrid, 1983. 
A la hora de aprobar y confirmar las Ordenanzas, resulta evidente el seguimiento de la Ley de 1856 , donde se señala que los acuerdos del Ayuntamiento podían ser inmediatamente ejecutivos si trataban sobre asuntos relativos a la resolución inmediata de problemas relacionados con la sanidad, las obras públicas, etc., ${ }^{23}$ mientras que se requiere la aprobación de la Diputación Provincial para que sean ejecutivos los acuerdos tomados por los Ayuntamientos en materia de presupuestos, pleitos, etc. ${ }^{24}$ Además, hay casos específicos que necesitan la aprobación de la Diputación Provincial y del gobernador de la provincia, tales como la formación y reforma de las Ordenanzas municipales y rurales. Si no se llegaba a un acuerdo entre la Diputación y el gobernador, debía remitirse el original de las Ordenanzas al Ministerio de Gobernación, para que, oído el Consejo de Estado, tomara una resolución definitiva. ${ }^{25}$

Otra posibilidad era que las Ordenanzas, por orden del gobernador civil, fuesen elaboradas por la Junta Superior Civil en forma de proyecto. Este pasaría al Ayuntamiento para que allí se hicieran las mejoras oportunas y convenientes, luego al Claustro de miembros de la Real Audiencia y, por último, al Real Acuerdo que, a través de sus oidores, proponía una serie de observaciones que podían ser aceptadas o rechazadas. Finalmente, el gobernador político de la ciudad realizaba la aprobación definitiva. De este tipo serían unas Ordenanzas de La Habana de $1855,{ }^{26}$ donde, a pesar de haber sido aprobadas en fechas anteriores, encontramos un planteamiento muy similar al que dictará luego la Ley de $1856 .{ }^{27}$ Cabe insistir en la cuestión apuntada anteriormente sobre el seguimiento de postulados similares a los de la ley de 1856 por cuanto en estas fechas está vigente de nuevo en la Península la ley de 3 de febrero de 1823 (Instrucción para el gobierno económico-político de las provincias)

23 Ley de Ayuntamientos de 1856, Título III, Cap. I, art. 126.

24 Ibídem.

25 Ley de Ayuntamientos de 1856, art. 128, párafo 1.

26 Ordenanzas municipales de la ciudad de La Habana, Habana, 1855.

27 Don José de la Concha, gobernador político de la ciudad en estos momentos, las aprobará el 24 de diciembre de 1855, incluyendo en el escrito de aprobación la orden para que entren en vigor el 1 de enero de 1856. 
$y$, curiosamente, las coincidencias de estas Ordenanzas con los dictados de dicha ley son prácticamente nulas.

\section{Las ordenanzas de los municipios de la isla de Cuba}

\section{La práctica de la aprobación}

Cuento con algunos ejemplares de Ordenanzas de municipios cubanos que solicitaron su aprobación al Ministerio de Gobernación, acto en el que intervenía activamente el Consejo Real en su sección de Ultramar. Según estas actas de aprobación, existía una real orden del Ministerio de Estado, con fecha de 6 de agosto de 1857, por la cual era preceptivo enviar los textos de Ordenanzas municipales (que ya estaban en vigor con carácter provisional en el municipio de origen) a la sección de Ultramar del Consejo Real, con vistas a la elaboración, por parte de ésta, de un informe donde se valorara la conveniencia de que esos textos entraran en vigor mediante la aprobación o la necesidad de rectificarlos para conseguir su conversión en norma ejecutiva. Una vez visto este informe por el ministro de Estado y Ultramar, el texto era enviado al monarca y después debía enviarse una carta al gobernador capitán general de la isla de Cuba para que entrasen en vigor.

Así, en el expediente sobre el proyecto de Ordenanzas municipales para Santiago de Cuba, ${ }^{28}$ realizado en 1858, encontramos referencias claras para verificar el procedimiento seguido en la confirmación y aprobación real. Se inicia con una carta del vicepresidente del Consejo Real, dirigida a la Primera Secretaría de Estado de Ultramar, en la que se pide a la Sección de Ultramar que emita los informes oportunos sobre unos proyectos de Ordenanzas que han llegado al Ministerio de Estado solicitando su confirmación. A continuación aparece en el expediente el informe enviado al Consejo

28 Archivo del Consejo de Estado (en adelante, ACE), Sección de Ultramar, Gobernación varios 1851-1861, Caja 41. exp. 2344. Isla de Cuba. Ayuntamientos. Ordenanzas. Proyecto de las Ordenanzas municipales para Santiago de Cuba. 
Real por dicha Sección de Ultramar en el que se opina favorablemente acerca de la conveniencia de su aprobación por parte del gobernador del Estado, aunque se deja a la exclusiva competencia del ministro de Estado y de la Corona su aprobación definitiva. Por último, el vicepresidente del Consejo Real, a través de la Primera Secretaría de Estado de Ultramar, comunica al gobernador capitán general de la Isla la resolución definitiva. El texto de esta carta, similar en todos los casos consultados (que coinciden además por haber sido aprobados durante la Regencia de María Cristina), ratifica la confirmación real de las Ordenanzas y abre la vía para que entren en vigor en el municipio correspondiente.

Este texto podría ser considerado como el paradigma seguido por los distintos municipios cubanos a la hora de hacer efectiva una confirmación. Es decir, después de haber sido aprobadas en el municipio de origen por las autoridades del mismo y después de conseguir la aprobación de las autoridades superiores de la Isla, era preciso un requisito más - lo cual demuestra el carácter centralizador respecto a este punto-, el último, pero imprescindible para que las Ordenanzas adquirieran la categoría de ley de obligado cumplimiento.

Así, podemos ver cómo otras Ordenanzas consultadas (las de los municipios de Cienfuegos ${ }^{29}$ y Matanzas ${ }^{30}$ ) siguen, sin muchas variaciones, este modelo. Se trataría, por tanto, de Ordenanzas municipales necesitadas de una reforma, sobre la cual no se han puesto de acuerdo las altas instituciones de poder de la Isla y, por consiguiente, recurren al Ministerio de la Gobernación para conseguir su entrada en vigor definitiva, ya que de hecho están funcionando sin la confirmación final. No obstante, acudir en última instancia al Ministerio de la Gobernación para solicitar la confirmación parece ser una práctica seguida en todos los casos.

En cuanto a los temas abordados en este grupo de textos, encontramos una clara conformidad con las que pueden considerarse pautas generales de las Ordenanzas del siglo XIX, ya que al citar

29 ACE, Sección de Ultramar, Gobernación varios, Caja 41, expediente 2348.

30 Ibídem, expediente 2349. 
sus contenidos se alude a temas tales como la moral, la salubridad y seguridad pública, ornato y aseo de la población, abastos, diversiones y espectáculos públicos. Esta relación temática aparece, en la forma expresada, en los tres ejemplares de Ordenanzas consultados en el Consejo de Estado, aunque sólo se citan nominalmente los asuntos, pues en estos documentos no se incluye el texto completo de las Ordenanzas. ${ }^{31}$

Volviendo a las formas de confirmación, cabe señalar que la anterior no era la única pauta a seguir en Cuba para confirmar las Ordenanzas, ya que también conocemos casos distintos en los que bastaba la autoridad del gobernador civil para convertirlas en normas ejecutivas. El modelo seguido presentaría las siguientes características: el Gobierno Superior Civil de la isla redactaba un proyecto de Ordenanzas que era publicado en distintos ámbitos. Sobre este proyecto se recababan los informes de la Capitanía General, de la Intendencia de Ejército y de los Ayuntamientos más importantes de la isla, con el fin de establecer las modificaciones y adiciones que cada uno de estos organismos considerara oportunas. Una vez obtenidos los informes, el texto era reelaborado, introduciendo las modificaciones pertinentes y se configuraba un nuevo proyecto de Ordenanzas. Este último proyecto, así elaborado, era presentado al Real Acuerdo, ${ }^{32}$ para que emitiera su voto que, en última instancia, era puramente consultivo. Cuando éste era favorable, el gobernador capitán general daba su aprobación definitiva, dejando abierto el camino para los pasos siguientes, es decir, para la publicación y la entrada en vigor, ordenando a todas las autoridades y funcionarios públicos de la isla que las hagan cumplir y ejecutar. Lo habitual era que entrasen en vigor transcurrido un mes desde la aprobación definitiva. ${ }^{33}$

31 lbídem, expedientes 2344, 2348 y 2349.

32 Se trata de una institución que existía desde los primeros años de la conquista, siendo un órgano fundamental en el esquema gubernativo de las Reales Audiencias, pero que pervive aún en estas fechas, desapareciendo en 1861. Beneyto, Historia de la..., pág. 574.

33 Ordenanzas rurales de la Isla de Cuba, Habana, 1857. 


\section{Las ordenanzas rurales de la isla de Cuba}

Constituyen un caso especial ya que se trata de Ordenanzas municipales dictadas para todos los municipios de la isla y no para uno solo. Por ello, su elaboración no es competencia del Ayuntamiento del municipio, máxima autoridad local, sino que se hacen por dictado del gobernador civil, máxima autoridad provincial de la colonia. Esta cuestión determina, en buena medida, los contenidos de dichas Ordenanzas por cuanto no podrán incluir disposiciones puntuales sobre ciertos aspectos que, habitualmente, responden a los intereses de un solo municipio. Se trata, en definitiva, de Ordenanzas específicas sobre los problemas relacionados con el campo en todas sus vertientes: reglas de trabajo, de aprovechamiento de las tierras, de orden, de salubridad, etc. En ningún caso se alude a cuestiones particulares como podría ser la determinación del número de sesiones de los Ayuntamientos, de sus horarios, los sistemas para la elección, de sus miembros, etc., pues es obvio que no tienen ninguna relación con el funcionamiento político de los Ayuntamientos.

Estas Ordenanzas están formadas por un total de 8 títulos, divididos en capítulos, secciones y artículos, en los cuales se trata detalladamente sobre las materias apuntadas más arriba. La sola relación de los contenidos nominales del texto da una idea clara de cuáles eran los problemas sobre los que interesaba fijar pautas de conducta, siendo destacable, en términos generales, la moral de que están impregnados.

En el texto de las Ordenanzas se fijan las penas impuestas por las infracciones, lo cual remite nuevamente a la Ley de Ayuntamientos de 1856 donde se fijan las cantidades máximas que podrán ponerse como multa por incumplimiento de Ordenanzas de policía urbana y rural, pudiendo llegar al arresto si los penados fueran insolventes. ${ }^{34}$

34 Ley de Ayuntamientos de 1856, Título III, cap. I, art. 126, párrafo 3:"los reglamentos y disposiciones para la ejecución de las ordenanzas de policía urbana y rural, en las que no podrán variar las penas que el Código penal establece para los casos que en el mismo estén previstos, ni para los que no lo estén señalar otros castigos que multas, que no excedan de 80 rs. en las capitales de provincia, de 60 en las cabezas de partido y pueblos de mas de 1.000 vecinos, y de 40 en los demás, y en caso de insolvencia el arresto que no pase de tres dias, además del resarcimiento del daño causado". 
La diferencia estriba, únicamente, en las distintas monedas en que se fijan las penas, según se trate de Cuba o de la metrópoli. Por lo demás, a lo largo del articulado se encuentran referencias a los mismos cargos que en ese momento están dirigiendo los municipios de la Península e islas adyacentes.

La temática del texto informa exhaustivamente sobre cuál era el tipo de actividades realizadas en los pueblos de la isla, es decir, sobre cuestiones agropecuarias, de caza y de pesca, así como de las obligaciones a seguir para la conservación y aumento de las riquezas de dichos pueblos. Obviamente, un detallado análisis de estos contenidos proporcionaría un amplio conocimiento del tipo de población de las zonas rurales de Cuba, así como de la clase de sociedad que el Estado español pretendía formar en las mismas.

\section{Legislación estatal sobre Ultramar}

En este apartado, relativo al análisis de la normativa estatal para las colonias, se recogen los artículos y capítulos que las distintas constituciones españolas dedicaron a Ultramar, especialmente en lo referido a su división provincial y municipal, así como a sus posibilidades de participación en el nuevo sistema político. Además, se valoran también los puntos de las distintas leyes de Ayuntamientos y de organización provincial que hacían una referencia directa al territorio de Ultramar, hecho poco frecuente en la legislación española de régimen local común del siglo XIX.

Para abordar este asunto, es preciso hacer un breve repaso de la legislación general emanada del Estado español con relación a los territorios de Ultramar, para poder integrar la normativa municipal dentro del marco global de la administración del Estado. Por otra parte, un análisis de la legislación estatal proporciona numerosos puntos de referencia para establecer las relaciones de dichos territorios con el Estado español $y$, en consecuencia, permite fijar para cada uno de los componentes del binomio colonias-metrópoli una situación acorde con la realidad política del momento y, por supuesto, no distorsionada. Aunque se incluyen aquí normas comunes a 
todas las colonias, resaltaré las que hagan una alusión específica a la isla de Cuba.

Quizás es oportuno, llegados a este punto, recordar que con anterioridad al estallido de la revolución liberal en España, las Leyes de Indias regulaban la vida colonial. ${ }^{35}$ La necesidad de volver sobre ellas se debe a que, en muchas ocasiones, a pesar de la unificación pretendida, los textos aluden al cumplimiento de estas leyes, pues constituyen el marco jurídico a seguir en determinadas cuestiones, evitando así el compromiso de elaborar esas "leyes especiales" a las que tanto se aludió y que no llegaron a redactarse.

Dejando aparte las valoraciones sobre la pervivencia de estas Leyes de Indias en el siglo XIX, es evidente que el inicio de este resumen se remonta a la Constitución de Cádiz de 1812, ya que es a partir de esta fecha cuando el Estado español dispone de un marco jurídico uniforme. El tratamiento dado en este texto, tanto al territorio, como a los habitantes de las colonias es muy similar al dispensado al resto de los dominios españoles, aunque se advierten algunas peculiaridades que examinaremos a continuación, siguiendo un orden cronológico.

En la Constitución de 1812 se considera a las colonias como parte integrante de la nación española ${ }^{36}$ y son incluidas en el territorio español ${ }^{37}$-aunque se parte de una división provisional que debía ser revisada - ${ }^{38}$ lo cual permitía a los habitantes de las colonias ser considerados como ciudadanos españoles ${ }^{39}$ y disfrutar, al

35 Recop. Leyes de Indias, Libro V, Título II, Ley xxxii: "Que los salarios de los Corregidores de Señorio se paguen de los tributos dèl, y no de la Comunidad".

36 Constitución de 1812, Tít. I, Cap. I, Art. 1: "La Nación española es la reunión de los españoles de ambos hemisferios".

37 Constitución de 1812, Tít. II, cap. I, art. 10: "En la América septentrional: Nueva España con la Nueva-Galicia y península de Yucatán, Guatemala, provincias internas de Oriente, provincias internas de Occidente, Isla de Cuba con las dos Floridas..."

38 Ibídem, Título II, cap. I, art. 11: "Se hará una división más conveniente del territorio español por una ley constitucional, luego que las circunstancias políticas de la $\mathrm{Na}$ ción lo permitan".

39 Constitución de 1812, Título I, cap. II, art. 5: "Son españoles: Primero. Todos los hombres libres nacidos y avecindados en los dominios de las Españas, y los hijos de éstos". 
menos teóricamente, de una reconocida ciudadanía. ${ }^{40}$ Así, en la Constitución también se les otorgaban los derechos de ciudadano, al contar con representación en las Cortes, fijando fechas específicas para la celebración de juntas electorales de parroquia, de partido y de provincia, que se realizaban para nombrar los diputados a Cortes, aunque la representación de los habitantes de las colonias será bastante reducida en la práctica. ${ }^{41}$

Teóricamente, las colonias disfrutaban de las mismas posibilidades que el resto de la nación a la hora de enviar representantes a las primeras Cortes que se celebraron. Sin embargo, la realidad arroja un saldo bien distinto, en la medida que el número de representantes llegados a la Península desde las colonias fue muy reducido. Hasta hace poco, ${ }^{42}$ no se sabía exactamente el número de diputados que asistieron a las primeras Cortes de Cádiz, ${ }^{43}$ aunque había estudios al respecto - todavía no muy fiables, como señalan sus propios autores - que daban unas cifras aproximadas, basándose en los datos aportados por los "Diarios de Sesiones". Según estos trabajos, la isla de Cuba envió cuatro representantes a las Cortes recién convocadas, ${ }^{44}$ cifra muy reducida si la comparamos con el número de diputados enviados por otras provincias españolas, aunque resulta

40 Ibídem, Título II, cap. IV, art. 18: "Son ciudadanos aquellos españoles que por ambas líneas traen su origen de los dominios españoles de ambos hemisferios y están avecindados en cualquier pueblo de los mismos dominios".

41 Para una mayor información sobre este punto, véase Materiales para el estudio de la Constitución de 1812, Madrid, 1989.

42 Aunque no se pretende restar validez a las obras de Suárez y Artola, precisamente por haber sido los pioneros en la materia, conviene destacar los trabajos realizados en la actualidad por M." Teresa Berruezo que ha conseguido una importante ampliación del conocimiento sobre la materia, mediante un análisis detallado de los diputados americanos en las Cortes de Cádiz. Berruezo León, M." Teresa: La participación americana en las Cortes de Cádiz 1810-1814, Madrid, 1986.

43 Artola Gallego, Miguel: Los Orígenes de la España Contemporánea, 2." ed., vol. I, Madrid, 1975, págs. 462-464.

44 Suárez Verdaguer, Federico: Las Cortes de Cádiz, Madrid, 1982, págs. 24-48. Este autor recoge, además del número, los datos de filiación de los diputados procedentes de la Isla de Cuba: Jaúregui, Andrés (por La Habana). Teniente regidor y alguacil de La Habana. O'Gavan, Juan Bernardo (por la isla). Provisor y vicario general de la Habana. San Felipe y Santiago, marqués de. Súplente. Se llamaba Juan Clemente Núnez del Castillo y Molina, y era Grande de España. Santa Cruz, Joaquín. Suplente. Coronel de Milicias de la Habana. 
similar a la del resto de las colonias, pues sólo algunas de ellas aportaron un número importante de diputados, como es el caso del virreinato de Nueva España o del virreinato de Perú. ${ }^{45}$

Además de lo señalado en la Constitución de Cádiz de 1812, era necesario dotar al texto constitucional de una mayor capacidad de funcionamiento y de unas posibilidades reales de desarrollo. Por ese motivo, los decretos posteriores a la misma, tendentes a convertir en realidad lo señalado por la Constitución, contienen importantes referencias a las cuestiones de Ultramar y, en última instancia, configuran una concreción más precisa de los principios fijados en esencia en la ley superior.

Es enorme la cantidad de decretos de Cortes dictados con posterioridad a la aprobación de la Constitución, pues cualquiera de sus títulos, capítulos o artículos era susceptible de originar una resolución de este tipo. Sin embargo, nos centraremos sólo en aquellos que desarrollaron los principios constitucionales relativos a la organización de los Ayuntamientos y de las provincias, es decir, al régimen local y territorial del Estado.

La revisión de algunos de ellos permite comprobar cómo en estos textos se especifican, de forma detallada, los principios establecidos anteriormente, al tiempo que configuran las reglas más apropiadas para que tengan una aplicación real. Así, el decreto de 23 de mayo de $1812,{ }^{46}$ relativo a la formación de los Ayuntamientos constitucionales, señala en su artículo XII: "Como puede suceder que haya en las provincias de Ultramar algunos pueblos que por sus particulares circunstancias deben tener Ayuntamiento para su gobierno, pero cuyos vecinos no estén en el exercicio de los derechos de ciudadano, podrán sin embargo en este caso elegir entre sí los oficios de Ayuntamiento baxo las reglas prescritas en esta ley para los demás pueblos". El decreto fijaba unas condiciones especiales para los territorios de Ultramar, aunque hacía homogéneo a todos los dominios del Estado español, tanto las normas para formar Ayuntamien-

45 Ibídem, págs. 43-44.

46 Decreto CLXIII, de 23 de Mayo de 1812, sobre formación de los Ayuntamientos constitucionales. Fernández, Tomás Ramón y Santamaría Pastor, Juan Antonio: Legislación administrativa española del siglo XIX, Madrid, 1977, págs. 691-692. 
tos, como las establecidas para la elección de los oficios de los mismos. En definitiva, al igual que para los pueblos de la Península, se fijaba la posibilidad de crear Ayuntamientos constitucionales en aquellos pueblos donde la población ascendiera a mil individuos o donde el alto desarrollo de la industria, agricultura o ganadería lo hiciera aconsejable. Además, se fijaban unas fechas concretas para realizar la elección de los oficios (un día festivo del mes de diciembre) y se establecía un sufragio indirecto en dos grados: una junta de parroquia, formada por los habitantes de los pueblos de más de cincuenta vecinos, elegiría una junta de electores en criterio proporcional a su población (desde 9 electores en los pueblos que no lleguen a mil habitantes, hasta veinticinco en aquellos que pasaran de cinco mil vecinos) que serían los encargados de conferenciar para elegir a los oficiales. Respecto al número de oficiales, señalaba un número variable entre dos y dieciséis regidores —en proporción con el número de habitantes-, de uno a dos alcaldes, también en proporción a la población y de uno a dos procuradores síndicos, según el mismo criterio. El decreto fijaba, por último, la desaparición de los oficios perpetuos que ya había sido establecida en el artículo 312 de la Constitución. ${ }^{47}$

Un decreto de la misma fecha, ${ }^{48}$ con el que se pretendía dar desarrollo y facilitar la ejecución del artículo 325 de la Constitución, ${ }^{49}$ establecía las Diputaciones Provinciales en la Península y Ultramar. Dicho decreto en su artículo I recogía: "Que mientras no llega el caso de hacerse la conveniente división del territorio español, de que trata el artículo II, habrá Diputaciones provinciales en la Península e Islas adyacentes... Y en Ultramar las habrá en cada una de las provincias que expresamente se nombran en el artículo 10 de

47 Constitución de 1812, Tít. VI, Cap. I, art. 312: "Los alcaldes, regidores y procuradores síndicos se nombrarán por elección en los pueblos, cesando los regidores y demás que sirvan oficios perpetuos en los Ayuntamientos, cualquiera que sea su título y denominación".

48 Decreto CLXIV, de 23 de Mayo de 1812, sobre establecimiento de las Diputaciones provinciales en la Península y Ultramar. Fernández y Santamaría, Legislación administrativa española..., págs. 692-693.

49 Constitución de 1812, Tít. VI, Cap. II, art. 325: "En cada provincia habrá una Diputación llamada provincial, para promover su prosperidad presidida por el jefe superior". 
la Constitución, y además por ahora en la América Meridional, en el Perú la de Cuzco, en Buenos-Ayres la de Charcas, y en la Nueva Granada la de Quito; y en la América Septentrional, en NuevaEspaña la de San Luis Potosí, á que se agregue Guanaxuato; en Goatemala otra que se fixará en León de Nicaragua con la provincia de Costa-Rica, y en la isla de Cuba otra en Santiago de Cuba".

En estas fechas todavía era extensible la legislación general para los territorios ultramarinos por lo que todos los decretos aprobados serán aplicados en estas zonas donde, obviamente, incluyo a la Isla de Cuba.

Un decreto de 23 de junio de $1813^{50}$ continuaba integrando a las provincias de Ultramar en la normativa general. Así, el capítulo I dedicado a las obligaciones de los Ayuntamientos, hacía una referencia a las provincias de Ultramar en su artículo XXIII, donde se fijaban las fechas para convocar las elecciones de juntas electorales de parroquia de las que habrían de salir los electores de los pueblos que acudirían a las elecciones de partido. La convocatoria para las Cortes ordinarias propició la publicación de un decreto el 23 de mayo de 1812 sobre el modo en que debían celebrarse en las provincias de Ultramar las elecciones de diputados a Cortes. Según la instrucción que acompañaba a ese decreto, se debían formar Juntas preparatorias en una serie de capitales de Ultramar, entre las que se encontraba "Habana, capital de la isla de Cuba y de las dos Floridas". ${ }^{51}$ El mismo artículo regulaba la forma en que debían ser presididas dichas juntas, así como el modo de presentar los resultados a la autoridad superior, en este caso, el jefe político. ${ }^{52} \mathrm{La}$ única diferencia era cronológica y ello por razones obvias (distancia geo-

50 Decreto CCLXIX, de 23 de Junio de 1813, aprobando la instruccion (sic) para el gobierno económico-político de las provincias. Fernández y Santamaría, Legislación administrativa españla..., págs. 693-701.

51 Citado por Ferrando Badía, J.: Proyección exterior de la Constitución de 1812, en Artola, M., ed., Las Cortes de Cádiz, "Ayer", n. ${ }^{\circ}$ 1, pág. 215. La referencia ha sido tomada por Ferrando Badía de La Constitución de 1812, II, Publicaciones del Archivo General de la Nación, pág. 151.

52 Constitución de 1812, Cap. I, art. XXIII: "El último Domingo de Noviembre de 1813 en Ultramar, y el último Domingo de Setiembre de 1814 en la Península, Islas y posesiones adyacentes, y así sucesivamente cada dos años...". 
gráfica, diferencias horarias, etc), pero, al margen de ella, no existe ninguna diferenciación concreta entre las posesiones de Ultramar y la Península, por lo que debemos entender que cargos tan importantes en la futura vida de los municipios como el de jefe político fueron también exportados a las colonias, aunque pudiera tener otra denominación. ${ }^{53}$ Las atribuciones adjudicadas en el mismo a los Ayuntamientos y Diputaciones provinciales se hacían también extensivas a las instituciones de las colonias, lo cual nos reafirma, una vez más, en el escaso interés de las autoridades españolas por dictar una legislación específica que examinara la realidad y las necesidades de los territorios de América.

El regreso de Fernando VII supuso un vuelco en toda la normativa dictada al respecto $\mathrm{y}$, además, ese cambio afectó del mismo modo a las colonias que a los territorios de la Península e islas adyacentes. La vuelta a la situación anterior a los decretos dictados por las Cortes en 1812 y 1813 fue ordenada por dos textos de Fernando VII, el real decreto de 15 de junio de $1814^{54}$ y la real cédula de 30 de julio del mismo año ${ }^{55}$, por los que se abolía la legislación dada por las Cortes y se ordenaba, tajantemente, la vuelta a la situación anterior a 1808. La vuelta atrás originada por estas órdenes reales fue conflictiva para la Península en su aplicación y aún lo fue más en los territorios coloniales por cuanto la lejanía espacial hacía más complicado, si cabe, el cambio de una normativa tan importante cuando apenas si había pasado tiempo suficiente como para iniciar su cumplimiento.

53 En este sentido, el decreto de 23 de junio de 1823 señala en el Capítulo III, artículo VII, lo siguiente: "Para el señalamiento de sueldos de estos empleados (se refiere al jefe político), de los secretarios y subalternos en Ultramar, el Gobierno presentará á las Córtes para su aprobacion la cuota que crea más conveniente establecer atendidas todas las circunstancias".

54 "Real decreto de S.M. de 15 de Junio de 1814, por el cual se suprimen las Diputaciones provinciales y se manda que los papeles de sus Secretarías pasen á las respectivas Contadurías de provincia”. Fernández y Santamaría, Legislación administrativa española..., págs. 701-702.

55 "Real cédula de S.M. y Señores del Consejo, de 30 de Julio de 1814, por la cual se manda se disuelvan y extingan los Ayuntamientos y Alcaldes constitucionales, que se restablezcan los Ayuntamientos, Corregimientos y Alcaldes mayores en la planta que tenian en el año de 1808, con lo demás que se expresa". Ibídem. págs. 173-174. 
El retorno de los liberales al poder en 1820 determinó un nuevo cambio en el régimen municipal al ser aprobada la Instrucción para el gobierno económico-político de las provincias el 3 de febrero de 1823. ${ }^{56}$ Esta norma, conocida como "ley descentralizadora" supuso importantes cambios no sólo por corresponder a los principios liberales de los revolucionarios, sino porque gracias a ella el partido progresista conseguía imponer sus principios sobre el régimen local. Sin embargo, todo lo expuesto hasta aquí pudo resultar beneficioso para el territorio peninsular - aunque apenas tuvo vigencia en esa etapa del liberalismo-, pero con respecto a los territorios de Ultramar no parecía suficiente un cambio de régimen político, pues la obligatoriedad de regirse por las mismas normas que unos territorios con los que nada tenían que ver - salvo el dominio político- siguió sin ser subsanada.

El carácter versátil de la historia política de España en el siglo XIX, forzó la promulgación de un buen número de constituciones, en función del sector que ocupara el poder en cada momento. Sin entrar a valorar este hecho, lo que interesa reseñar es que desde la Constitución de 1837, se fija un nuevo criterio con respecto a las colonias, según el cual ya no estarán plenamente integradas en la normativa común, sino que dispondrán de leyes especiales. ${ }^{57}$ Desde esta fecha, hasta 1869, los textos constitucionales omitirán las referencias concretas a la integración de las colonias en el derecho común, tal y como ocurría en la Constitución de 1812, pasando a señalar, mediante artículos adicionales, la futura elaboración de leyes especiales, de cuya utilidad y puesta en práctica ya nos ocupamos en otro punto de este apartado. ${ }^{58}$

La Constitución de 1869, al ser redactada en nombre de la nación española, vuelve a incluir en su articulado referencias concretas a las colonias, aunque no se trate ya de una integración total

56 Para profundizar en el alcance y contenidos de esta ley, véase Castro, Concepción de: La Revolución Liberal y los municipios españoles, Madrid, 1979, págs. 98-102.

57 Constitución de la Monarquía Española de 1837, Artículos adicionales, art. 2: "Las provincias de Ultramar serán gobernadas por leyes especiales".

58 Constitución de la Monarquía Española (23 de mayo de 1845), Artículo Adicional, art. 80: "Las provincias de Ultramar serán gobernadas por leyes especiales". 
como ocurría en Cádiz. ${ }^{59}$ Esta Constitución, surgida de un nuevo proceso revolucionario, resultaba mucho más liberal que las anteriores y, sobre todo, abría la posibilidad de establecer pactos con los representantes de Cuba, a la hora de modificar el régimen político de la Isla. Conforme avanza el siglo, la legislación refleja de forma cada vez más clara el grado de tensión existente en Cuba en relación con sus deseos de autonomía política. Así, el proyecto de constitución federal de la república española de 17 de julio de 1873 , aunque no llegó a entrar en vigor, suponía una clara concesión a la autonomía cubana, pues consideraba a la Isla como un estado más de la federación, ${ }^{60}$ concediéndole, en este sentido, toda la autonomía económico-administrativa y política que a los demás estados de la nación. Incluso, en esta constitución se dedica el título XIV a los Municipios, resaltando en el artículo 106 que disponen "en todo lo municipal autonomía administrativa, económica y política". La vuelta a la situación política anterior dio lugar a la realización de otro texto constitucional, nuevamente monárquico, donde se insiste en la idea de leyes especiales para las provincias Ultramarinas, aunque se aprecia un cierto trato de privilegio para la isla de Cuba, ${ }^{61}$ en consonancia con el interés por evitar conflictos que dieran lugar a su pérdida. La Constitución de 1876 será el último texto en vigor del

59 Constitución de la Monarquía Española (l de junio de 1869), Título X (De las provincias de Ultramar), Art.108: "Las Cortes Constituyentes reformarán el sistema actual del gobierno de las provincias de Ultramar, cuando hayan tomado asiento los diputados de Cuba o Puerto Rico, para hacer extensivos a las mismas, con las modificaciones que se creyeren necesarias, los derechos consignados en la Constitución".

60 Proyecto de Constitución Federal de la República Española, Título I, Art. I: "Componen la Nación española los Estados de Andalucía Alta, Andalucía Baja, Aragón, Asturias, Baleares, Canarias, Castilla la Nueva, Castilla la Vieja, Cataluña, Cuba, Extremadura, Galicia,..."

61 Constitución de la Monarquía Española (30 de junio de 1876), Título XIII (Del gobierno de las provincias de Ultramar), Art. 89: "Las provincias de Ultramar serán gobernadas por leyes especiales; pero el Gobierno queda autorizado para aplicar las mismas, con las modificaciones que juzgue convenientes y dando cuenta a las Cortes, las leyes promulgadas o que se promulguen para la Península. Cuba y Puerto Rico serán representadas en las Cortes del Reino en la forma que determine una ley especial, que podrá ser diversa para cada una de las dos provincias.

Artículo transitorio. El Gobierno determinará cuándo y en qué forma serán elegidos los representantes a cortes de la isla de Cuba". 
siglo XIX y, en consecuencia, será el que rija en Cuba hasta su independencia.

La conclusión de este apartado lleva a confirmar un punto importante, el referido a que la normativa estatal hizo que Cuba estuviera plenamente integrada en el régimen político impuesto por la metrópoli $\mathrm{y}$, por extensión, en el régimen municipal dictado desde las instituciones centrales, lo cual conllevaba, sin ninguna duda, un férreo control de los asuntos cubanos y, en consecuencia, un fuerte rechazo al mismo por parte de la población de la Isla.

\section{Las reformas de los Ayuntamientos de la isla de Cuba}

En este apartado se establece un estudio sistemático de los diversos intentos de reforma municipal que, aun contando con la autorización y el apoyo metropolitano, dejan entrever la dependencia de la colonia y, sobre todo, informan del interés de dichos proyectos por configurar un nuevo modelo de funcionamiento para los municipios de la Isla. Además, en este apartado - con el fin de no aislar el tema de las reformas de la perspectiva histórica- se hace un repaso de la situación municipal de la isla de Cuba desde su conquista, lo cual permite establecer de forma clara cómo Cuba fue un caso ciertamente atípico dentro del panorama de los territorios de Ultramar. En síntesis, Cuba se mostró distinta al resto de los territorios porque, curiosamente, aunque fue el último en acceder a la independencia, demostró, desde un principio, unos intereses autonómicos más fuertes que los del resto de las colonias, como demuestra, en este sentido, la alta operatividad de sus municipios.

\section{La situación anterior}

Desde el inicio de la conquista de los nuevos territorios el sistema municipal imperante en la península fue trasplantado a ellos por cuanto contribuía a fortalecer los intereses de dominio perseguidos por la monarquía española. De este modo, los problemas exis- 
tentes en la institución municipal española fueron también trasladados al Nuevo Mundo, a saber: la enajenación a perpetuidad de los oficios municipales, ${ }^{62}$ la aceptación de gobiernos oligárquicos, la intervención de la corona en los nombramientos, etc. Sin embargo, los municipios de las islas obtuvieron algunas concesiones, motivadas fundamentalmente para evitar cualquier problema de sublevación. Así, los concejos de las colonias durante el Antiguo Régimen podían elegir a sus alcaldes, aunque tuvieran que aceptar la institución del corregidor o la designación real de regidores perpetuos. Se trataba, en definitiva, de "una situación de sincretismo" 63 en la que convivían la designación real de los altos cargos y el "sufragio vecinal" para designar las vacantes de los mismos. El caso del territorio que nos ocupa, Cuba, es quizá uno de los más significativos en cuanto a la fuerza ejercida por sus municipios para obtener un cierto grado de autonomía en la elección de sus altos cargos de gobierno, ya en el siglo XVI. ${ }^{64}$

A partir de esas fechas, la orientación de los problemas no fue modificada. Un rápido repaso a las consultas realizadas por los poderes de las islas al Consejo de Estado, es suficiente para concluir que en 1848 la situación de los municipios coloniales era aún más lamentable que la vivida en los peninsulares por cuanto los cargos de Ayuntamiento muestran rasgos idénticos a los existentes en la metrópoli en fechas anteriores, es decir, durante el Antiguo Régimen. Basta, por poner un ejemplo, con la prueba que nos proporciona una solicitud de 27 de octubre de $1848{ }^{65}$ para nombrar un corregidor presidente de Ayuntamientos, aunque en este caso podemos pensar que se trata, tan sólo, de seguir la misma reglamenta-

62 La venta de oficios en Indias es una cuestión aún sin resolver, aunque se han realizado ya excelentes trabajos sobre el tema. Parece claro que antes de 1606 los oficios jurisdiccionales (aquí entran, obviamente, los cargos de Ayuntamiento) no podían ser vendidos en Indias, porque regían allí los mismos preceptos jurídicos vigentes en la Corona de Castilla, aunque no pueda afirmarse lo mismo para los oficios de Hacienda. Sobre este punto, véase Tomás y Valiente, Francisco: La venta de oficios en Indias (1492-1606), Madrid, 1982.

63 Pérez de Tudela, Juan: El Estado Indiano, págs. 553 y ss.

64 Ibidem, págs. 554-555. Este autor señala que Cuba es un ejemplo de "una fuerza 'vecinal' que logró hasta 1556 la participación del concejo abierto al menos en la elección de los alcaldes, y aún después de esas fechas, en la de los regimientos no perpetuados".

65 ACE, Sección de Ultramar, Gobernación varios, Caja 40. 
ción que rige en la metrópoli, ya que la Ley de Ayuntamientos de 1845 señalaba la posibilidad de que se nombraran cargos de estas características. ${ }^{66}$ En cualquier caso, bien se trate de una vuelta radical al Antiguo Régimen o de una adecuación a lo ordenado por la Ley de Ayuntamientos de 1845, la cuestión es bastante clara: los municipios de Ultramar siguieron siempre el modelo impuesto por la metrópoli, de tal manera que si se propugnaba una vuelta al Antiguo Régimen, ésta llegaría, tarde o temprano, a las colonias y si se dictaba una ley de Ayuntamientos para la Península e islas adyacentes, también acabaría por regir en las lejanas islas coloniales, aunque no fuera dictada expresamente para ellas.

\section{El inicio de las reformas}

La idea de reformar los Ayuntamientos de la isla de Cuba parte de 1844, como demuestra una carta del capitán general de la isla de Cuba de 31 de enero de $1844,{ }^{67}$ dirigida al Ministerio de Ultramar para informar del deplorable estado del Ayuntamiento de La Habana y de la necesidad de una reforma. En ella se recoge que este Ayuntamiento se compone de dos alcaldes, un síndico y 17 regidores. Los alcaldes son electivos y se relevan cada año; el síndico podía ser reelegido, mientras los regidores eran perpetuos. Los problemas eran evidentes:

- Las regidurías perpetuas eran ocupadas por tenientes que compraban sus destinos y que, al ser muy cara la compra, para obtener ingresos y satisfacer al propietario, tomaban el cargo como un medio para su subsistencia.

- Mala administración de los fondos públicos. En épocas anteriores la administración de esos fondos era realizada por comi-

66 Ley de organización y atribuciones de los Ayuntamientos de 8 de enero de 1845, Tít. II, art. 10: "El Rey, sin embargo podrá nombrar libremente un Alcalde Corregidor en lugar del ordinario, en las poblaciones donde lo conceptúe conveniente". Evidentemente, el cargo tiene unas connotaciones bien distintas a las planteadas en la petición hecha por Cuba, pero conviene reseñar la posible relación.

67 ACE, Sección de Ultramar, Gobernación varios, Caja 41, expediente 2820. 
siones particulares nombradas por el capitán general, pero luego volvió la administración $-\mathrm{y}$ sobre todo la recaudación - a los Ayuntamientos.

- Los alcaldes ordinarios ejercían la jurisdicción en primera instancia (es decir la relativa a lo contencioso, civil y criminal), con facultad para asesorarse por cualquiera de los abogados de la ciudad. ${ }^{68}$

Según el autor de la carta, esto entrañaba muchas discrepancias por cuanto había demasiados abogados en la ciudad para elegir (el número era superior a seiscientos).

La propuesta del capitán general era:

1. - que los regidores ejerzan por sí el cargo, sin poderlo transmitir, sino a un hijo o un inmediato sucesor (es evidente que se acepta la propiedad del cargo, aunque no se admita la reventa del mismo en miembros de otra familia).

2. ${ }^{\circ}$-que los alcaldes vean limitada su jurisdicción a ejercer funciones municipales (se supone que de carácter administrativo) y de jueces de paz.

Ante esta solicitud, la Junta de Ultramar dio su informe el 17 de mayo de 1844, diciendo:

1. - que no se debía hacer novedad en la legislación vigente sobre los oficios municipales y su servicio por tenientes.

2. - - que la Junta tenía entendido que en el Ministerio de Gracia y Justicia existía un expediente sobre división territorial de la Isla y el modo de establecer en ella los juzgados de primera instancia.

3. - que mientras se resolvía dicho expediente, las Audiencias y el capitán general se encargaran de que los alcaldes y Ayuntamientos llevaran con celo sus deberes.

68 El Real Decreto de 1834, dictado en España sobre los Alcaldes, dispone de un excelente trabajo de Morillo Velarde, José I.: El alcalde en la administración española, Sevilla, 1977. Aquí se aprecian nuevamente las concomitancias entre la legislación dictada para España y la legislación de Ultramar. 
El 24 de junio de 1844 una comisión especial, creada a tal efecto, presentó un informe por el que se decía que con respecto a los oficios de regidores se adoptaran las disposiciones recogidas en un real decreto que aparecería con posterioridad (el decreto de 21 de julio de 1844). Con respecto a la jurisdicción ordinaria se dice que hay que suprimir el hecho de que los alcaldes tengan jurisdicción ordinaria y para suplir aquellos juzgados debían crearse en La Habana dos tenencias más, una en Matanzas, una en Santiago de Cuba y otra en Puerto Príncipe y que en el resto de las zonas (Santiago de las Vegas, Santa María del Rosario, San Juan de Jaraco y San Antonio Abad) el capitán general proveyera lo conveniente, bien sea por agregación a otros partidos en que haya teniente gobernador, o bien creando estos empleados donde lo estimara necesario. Los tenientes de gobernador legos se titularían, desde entonces, alcaldes mayores y así tendrían jurisdicción ordinaria en todos los asuntos judiciales de sus respectivos partidos y serían asesores natos, en los asuntos de gobierno, de los gobernadores y de los tenientes de gobernador.

Por fin, la Junta de autoridades del Ministerio de Gracia y Justicia dio un real decreto el 21 de julio de 1844 sobre el que hicieron propuestas de modificación y de introducción de novedades las Audiencias de La Habana y Puerto Príncipe, propuestas que, al no ser coincidentes entre sí, hicieron posible la aplicación íntegra del texto mencionado. En él se dictaminaba, entre otras cosas, la supresión de los oficios perpetuos - según fueran vacando-, la indemnización a los propietarios y el nombramiento interino para las vacantes por parte del capitán general gobernador.

A pesar de no ser aceptadas las propuestas de las Audiencias y de no ser recogidas, por tanto, en el decreto, el examen de sus informes es bastante revelador acerca de cuáles eran las pretensiones de las instituciones administrativas de la Isla. En realidad no difieren sustancialmente, ni se apartan en demasía, de la normativa vigente en la metrópoli.

Así, el Informe de la Audiencia de la Habana hacía una propuesta por la cual serían elegibles: los que teniendo la calidad de vecinos sean, a la vez, propietarios de bienes raíces, comerciantes 
con escritorio, mercaderes con tienda abierta, abogados, médicos y catedráticos de ciencias y artes en la Universidad que ejerzan estas profesiones y los dueños de establecimientos o fábricas en las que se elaboren ciertos géneros para la venta al por mayor. Este grupo de elegibles podría ocupar cargos de Ayuntamiento por un tiempo máximo de tres años, renovándose anualmente por terceras partes.

El Informe presentado por la Audiencia de Puerto Príncipe era mucho más amplio y, por consiguiente, más explícito que el anterior. Según este informe debían cesar los regidores perpetuos, así como las atribuciones del fiel ejecutor y de alférez mayor que serían ejercidas por los regidores que cada Ayuntamiento nombrara para tal fin el primer día de cada año. Los alcaldes y síndicos permanecerían en sus oficios por espacio de dos años, mientras los regidores ocuparían los suyos durante cuatro.

Las elecciones las realizaría el gobernador de entre una terna presentada por las Audiencias. Para ser elegibles se requerían condiciones que, en algunos casos, resultaban claramente lesivas - cuando no racistas o discriminatorias - para la población autóctona de la Isla: proceder de casta blanca desde tiempo inmemorial, ser de notorio españolismo y acreditada honradez, así como sumisos a las autoridades. Poseer una fortuna holgada, ser de capacidad moral y aptitud física para desempeñar el cargo, tener vecindad con casa abierta en el distrito por lo menos un año antes y ser mayor de edad. Podían quedar excluidos: los extranjeros - aunque naturalizados-, los solteros, los clérigos, los empleados públicos en activo servicio, los presentados a espera con curso o quiebra, los procesados por delitos políticos o comunes, los arrendadores de bienes del Ayuntamiento y los dueños o arrendadores de oficios enajenados. Además, podían excusarse de ser elegibles: los mayores de 60 años y los imposibilitados por enfermedad $u$ otra causa, siempre que fuera aceptada por el gobernador.

Ninguna de estas propuestas fue aceptada y, como señalaba antes, se puso en vigor el decreto realizado por el Ministerio de Gracia y Justicia. Sin embargo, la mayoría de estas cuestiones serán recogidas en el proyecto de reglamento de régimen local elaborado 
con posterioridad, aunque sea también un órgano oficial el encargado de su redacción.

A partir de este momento, las solicitudes hechas por los Ayuntamientos de la isla de Cuba no plantean soluciones reformistas, sino que, aceptando la dinámica que les ha sido impuesta, están encaminadas a conseguir algunas mejoras administrativas de carácter concreto en los distintos pueblos o en el término general de la Isla. Así, se suceden varias peticiones, tales como la creación de una Guardia Civil en la Isla, ${ }^{69}$ un proyecto de organización civil, ${ }^{70}$ sobre reducción de diferentes juntas generales de la isla de Cuba a cuerpos consultivos y reforma, al efecto, de la secretaría de Gobierno de aquella Capitanía General, ${ }^{71}$ sobre formación de presupuestos municipales provinciales y de gobierno para la isla, ${ }^{72}$ del Ayuntamiento de Matanzas sobre que se le concedan nuevos arbitrios municipales para la construcción de diferentes obras públicas, ${ }^{73}$ del gobernador capitán general de la isla sobre la reforma que ha hecho en los presidios, ${ }^{74}$ etc. La respuesta dada por la Sección de Ultramar del Ministerio fue afirmativa en la mayoría de las ocasiones, pero no parece que se arreglaran muchos de los problemas de fondo con logros tan parciales. Hay que esperar hasta el año 1854 para que se afronte la realización de un proyecto global de reforma de los Ayuntamientos de la isla de Cuba, ${ }^{75}$ concretamente el titulado "Proyecto de bases y reglamento para la reorganización de los Ayuntamientos de la isla de Cuba", ${ }^{76}$ el primero con entidad suficiente.

\section{El proyecto de reglamento de régimen local de 1854}

El proyecto de bases y Reglamento redactado por la Junta de Ultramar se configura como una fuente más para el estudio del mude 1851.

70 Ibídem, expediente 8312.

71 Ibídem, expediente 8313. Año de 1851.

72 Ibídem, expediente 8315.

73 Ibídem, expediente 9098. Año de 1851.

74 Ibídem, expediente 9099. Año de 1851.

75 Ibídem, expediente 2820. Año de 1854.

76 Ibídem, expediente 8514. 
nicipio cubano. En este punto, cabe advertir de la controversia existente entre los juristas a la hora de definir qué son los Reglamentos $\mathrm{y}$, sobre todo, qué lugar ocupan en el derecho administrativo, ${ }^{77}$ es decir, ¿son fuente de derecho administrativo o son actos administrativos?, ¿existen diferencias entre reglamentos estatales y reglamentos locales?. En cualquier caso, se trata de una polémica entre juristas ${ }^{78}$ en la que no entraré porque no aportaría nuevas perspectivas al trabajo. Quizás lo único que merece ser reseñado es que este Reglamento ha sido considerado en nuestro caso como una fuente histórica, obviando así la discusión sobre si se trata de una fuente de derecho o si pertenece al ordenamiento jurídico estatal. En definitiva, me interesa más conocer los contenidos de este Reglamento que valorar sus características jurídico-formales.

La cuestión más relevante es que no fue elaborado por los municipios para regular una esfera de actividad determinada (cometido que parece ser el común a los Reglamentos), sino que fue redactado por una institución del poder estatal, la Junta de Ultramar, que lo realiza con una finalidad mucho más ambiciosa, la de organizar la vida política de los municipios a través de unas disposiciones sobre sus Ayuntamientos, tomando en consideración parte de los informes a los que hemos aludido anteriormente.

Lo primero a tener en cuenta es señalar cuál puede ser el origen del mismo, cuestión ésta que resulta bastante sencilla de aclarar, simplemente con echar un vistazo a la legislación española de la época sobre los Ayuntamientos. Una vez más se confirma la existencia en la Isla de unas notorias influencias de la legislación metropolitana, pues el articulado del mismo coincide básicamente con los apartados de algunas de las leyes de Ayuntamientos elaboradas para la Península e Islas adyacentes. Aunque no se hace alusión en ningún momento a dichas leyes, tanto la fecha de su elaboración como sus contenidos, nos remiten a la Ley Municipal de 1840, de carácter netamente centralizador, que fue aprobada en una legisla-

77 Sobre esta cuestión, véase Embid Irujo, Antonio: Ordenanzas y Reglamentos..., págs. 605-680.

78 Ibídem, pág. 610. Alude a las posiciones encontradas de Boquera Oliver y García de Enterría. 
tura presidida por un gobierno moderado. Esta ley provocó numerosos problemas en España ya que su derogación por parte de la regente María Cristina derivó en el golpe de Espartero, la huida de la regente y el inicio de la Regencia de aquél. ${ }^{79} \mathrm{El}$ motivo de basarse en la Ley de 1840 no puede estar relacionado con la proximidad temporal, pues se había dictado posteriormente otra Ley de Ayuntamientos para la Península, la de 8 de enero de 1845. El hecho de haberse decantado en la elaboración del Reglamento por la Ley de 1840 lleva implícito un reconocimiento de mayor validez para la misma en relación con los problemas de la isla, además de definir, en cierto modo, el espíritu de sus redactores, porque la Ley de 1840, aunque centralizadora, permitía un régimen municipal mucho más representativo y menos endurecido que el impuesto después por la de 1845. Además, cabe suponer un cierto ánimo de enfrentamiento al identificar sus postulados con los de una ley tan controvertida como fue la de 1840.

En cualquier caso, el Reglamento tratará de una serie de cuestiones en las que aparecen los mismos principios que en la mencionada Ley. Más aún, observamos que las referencias a los cargos coinciden plenamente con lo visto en ella $\mathrm{y}$, además, confirman la hipótesis de que la legislación del territorio peninsular fue trasladada a Ultramar, aunque en las leyes de Ayuntamientos de la época sólo se mencione su aplicación en la Península e islas adyacentes e incluso no se dicten con la intención de regir también en las colonias todavía pertenecientes a España. Una comparación sencilla nos proporciona la certeza de lo contrario, es decir, las normas vigentes en la isla tendrán siempre como punto de referencia las de España, con la única diferencia de aplicarse allí en unas fechas posteriores y de introducir pequeñas variantes que no modifican sustancialmente la esencia doctrinal de las mismas.

La realización de un análisis comparativo del Reglamento de Régimen Local y de la Ley de Ayuntamientos de 1840 proporciona numerosos datos para establecer la casi total identidad entre uno y otro. Sin embargo, reproducir aquí la comparación línea a línea

79 Castro, Concepción de: La revolución liberal..., págs. 154-160. 
de ambos textos podría dar lugar a un resultado demasiado farragoso que nos haría perder la atención sobre sus principios comunes. Sin duda, es más oportuno señalar las pautas generales que, como recoge el propio texto del Reglamento serán puntualizadas y detalladas en él. ${ }^{80}$ Pasando al análisis de este Reglamento, cabe hacer una breve alusión a sus aspectos formales, señalando que consta de una introducción y siete capítulos, divididos en artículos, cuyo orden numérico no está especificado por tratarse sólo de un proyecto.

En la parte introductoria se regulan los aspectos genéricos, encaminados a sentar las bases de la futura reglamentación, bases sin las cuales sería inútil el Reglamento y cualquier otra normativa. Así, se reconoce la existencia de Ayuntamientos en todas las ciudades y villas de la isla de Cuba, siempre que cumplan los requisitos fijados en las Leyes de Indias, se reconoce doctrinalmente la elección de los cargos de dichos Ayuntamientos, que se regulará en un capítulo concreto, dictaminando de antemano que deben desaparecer todos los oficios perpetuos, para lo cual se fija un sistema tremendamente sencillo: una vez muertos sus titulares el oficio desaparecerá y no podrá volver a ser ocupado por el mismo procedimiento. No obstante, se incluye una cláusula de indemnización para los herederos del oficio que remite necesariamente al principio liberal de reconocimiento de la propiedad.

El Ayuntamiento, entendido como órgano de gobierno de los municipios, estará formado en todas partes por alcaldes, tenientes de alcalde, regidores y síndicos y un número igual de suplentes, siendo éste un artículo que será explicitado a lo largo del Reglamento, haciendo aquí sólo una descripción nominal.

Aunque se ha señalado que los Ayuntamientos serán electivos, debemos entender esta cuestión para una primera vuelta, ya que el nombre de los individuos que ocuparán esos cargos saldrá de una terna propuesta por los Ayuntamientos (no se hace referencia a que la terna se forme con los elegidos por los vecinos, lo cual destruye

80 La comparación línea a línea necesitaría de la introducción de una numeración lógica para hacer más cómoda la comprensión, pero ello habría obligado también a una elucubración porque no hay ninguna referencia para conocer su ubicación exacta en el texto. 
ese principio de sufragio) a pluralidad de votos que se entregará al gobernador capitán general para que decida. ${ }^{81}$

\section{Conclusiones}

El resultado del análisis proporciona dos conclusiones fundamentales: la exportación de la legislación española a Cuba, como elemento de presión, y la centralización impuesta por el Estado español, como garantía de control y de dominio.

Ciertamente, el resultado final confirma las hipótesis planteadas al comienzo, ya que el examen de la normativa, tanto estatal como local, permite afirmar que la legislación imperante en la Corona de Castilla primero y en España después, fue trasladada a las colonias sin modificaciones sustanciales.

Concretamente, en la cuestión municipal, la normativa conoció un proceso idéntico en su evolución, al haber podido constatar que los procesos de elaboración, aprobación y confirmación siguen cauces similares a los encontrados en España. Lo mismo ocurre en cuanto a los cambios realizados en aquéllos conforme avanza el siglo XIX. En síntesis, las normas que rigieron en Cuba en esta materia partían de principios idénticos, pues al exportarlas, también se exportaba su espíritu doctrinal. En consecuencia, las variaciones sólo aparecen en pequeños aspectos puntuales que no alteraban su esencia.

El traslado de la normativa dio lugar a problemas de todo tipo que, unidos a otro grupo de causas, desembocaron en la independencia. Las dificultades surgieron, fundamentalmente, ante la incomprensión mostrada por las autoridades españolas, que pretendieron instaurar el mismo modelo en zonas con grandes y múltiples disparidades. Las formas de vida de la isla de Cuba no podían coincidir con las de la metrópoli por circunstancias muy diversas, pero que, en última instancia, estaban relacionadas con la distancia entre am-

81 Obviamente, la identidad con el informe presentado por la Audiencia de Puerto Príncipe, no puede ser casual. 
bos países. Sin pretender llegar a un determinismo exacerbado, ni siquiera a un determinismo geográfico, no podemos olvidar que la situación geográfica y el propio clima producían un evidente distanciamiento en las formas de vida, comportamientos, hábitos, costumbres, motivaciones, etc., y, en definitiva, en la mentalidad de los dos grupos de población. Sin embargo, los sucesivos gobiernos metropolitanos no consideraron las notorias diferencias, pues no era lógico aplicar las mismas leyes a grupos sociales tan distintos étnica, cultural y antropológicamente. Al hilo de lo planteado, resulta significativo, por cuanto tiene de imposición, la elaboración de unas Ordenanzas rurales (repletas de recriminaciones), basadas en una moral que, probablemente, no tenía ninguna relación con los principios éticos de la sociedad cubana.

Abundando en la conclusión anterior, cabe señalar que el Estado español no llegó a comprometerse de forma real con los intereses de Cuba. Así, aunque en la primera etapa del dominio español existía una legislación para los territorios de Indias, lo cierto es que las disposiciones allí recogidas no eran radicalmente distintas a las fijadas por el derecho castellano. A lo sumo, las variaciones se producían a la hora de configurar una estructura de órganos de poder más acorde con la realidad de un territorio ocupado - que debía ser sometido y controlado- que con la de una parte integrante del territorio español. En cualquier caso, igualdad en las normas y diferencias discriminatorias para agudizar la dominación. Esta falta de respeto para con las necesidades de Cuba se hace más patente, si cabe, cuando el Estado español, ya en fechas muy cercanas a la independencia, se resistió sistemáticamente a confeccionar esas "leyes especiales", siempre anunciadas como la panacea universal que remediaría todos los problemas, pero nunca llevadas a la práctica.

La segunda conclusión concuerda también con la hipótesis planteada al comienzo: la relativa a que el Estado español ejerció siempre un poder de carácter centralizador sobre la isla de Cuba. En la investigación se ha puesto de manifiesto la realidad de dicha hipótesis porque, si valoramos en su justa medida los procedimientos impuestos para conseguir la confirmación de las normas locales, encontramos una dependencia completa que se refleja en la incapaci- 
dad de los municipios cubanos para tomar decisiones sin contar con la aprobación de los poderes de la Isla — nombrados, por cierto, por la corona española - e incluso con la de los poderes centrales. En este sentido, el dominio español no estuvo basado en la violencia, salvo en casos muy aislados (Yara y Baire), sino en una prepotencia institucional que pudo ejercer gracias a la estructura de poder creada en la isla. ${ }^{82}$

82 Las relaciones entre España y Cuba disponen de un reciente estudio que permite trasladar mis hipótesis a espacios temáticos más amplios. Cayuela Fernández, J.G.: España y Cuba en el siglo XIX. El control de las relaciones coloniales, Madrid, 1993. 